\title{
Partial orchiectomy vs. radical orchiectomy for pediatric testis tumors
}

\author{
Lynn L. Woo ${ }^{1}$, Jonathan H. Ross ${ }^{2}$ \\ ${ }^{1}$ Department of Pediatric Urology, Rainbow Babies \& Children's Hospital, Cleveland, OH, USA; ${ }^{2}$ Department of Urology, Rush University Medical \\ Center, Chicago, IL, USA \\ Contributions: (I) Conception and design: All authors; (II) Administrative support: None; (III) Provision of study materials or patients: None; (IV) \\ Collection and assembly of data: None; (V) Data analysis and interpretation: None; (VI) Manuscript writing: All authors; (VII) Final approval of \\ manuscript: All authors. \\ Correspondence to: Lynn L. Woo, MD. Department of Pediatric Urology, Rainbow Babies \& Children's Hospital, 11100 Euclid Avenue RBC 2311, \\ Cleveland, OH 44106, USA. Email: lynn.woo@uhhospitals.org.
}

\begin{abstract}
While radical orchiectomy remains the gold standard for testicular cancer, partial orchiectomy has become a well-accepted organ-sparing approach for benign testicular tumors in pre-pubertal patients. The aims of testicular-sparing surgery include prevention of over-treatment, preservation of future hormonal and reproductive function, and provision of a durable cure. For pre-pubertal patients, who have a high likelihood of benign lesions, partial orchiectomy provides effective treatment, owing to the high reliability of scrotal ultrasound (US) and intraoperative frozen section. In adolescent and young adult patients, who are more likely to harbor malignant pathology, the role of partial orchiectomy is less clear. Testis-sparing surgery is being reported with greater frequency in the adult literature for small testicular masses and for situations in which radical orchiectomy would result in an anorchia. More recently, a testis-sparing approach has also been described for carefully-selected post-pubertal pediatric patients. This review will highlight the role of partial orchiectomy in pediatric patients ( $<18$ years old).
\end{abstract}

Keywords: Testicular neoplasm; child; adolescent; orchiectomy; frozen section

Submitted Dec 01, 2019. Accepted for publication May 18, 2020.

doi: $10.21037 /$ tau-19-815

View this article at: http://dx.doi.org/10.21037/tau-19-815

\section{Introduction}

Pediatric testicular tumors are rare, occurring in approximately 1 per 100,000 boys annually and accounting for only $1 \%$ of all pediatric solid tumors (1). A bimodal age distribution is observed, with the first peak in early childhood and a second, larger peak in young adulthood (2). Until the mid-1980s, the management of pediatric testis tumors followed guidelines for adult patients, which consisted of radical inguinal orchiectomy. This was largely based upon the assumption of a high rate of malignancy, which was supported by the results of several early pediatric tumor registries (1,3-5). Recognizing these results were possibly biased with over-reporting of malignant and rare tumors, subsequent single- and multi-center studies have since demonstrated a greater percentage of benign lesions in pre-pubertal patients, with teratoma being the most commonly-reported histology (6-9). Unlike in adult patients, teratoma behaves in a universally benign fashion in pre-pubertal boys and is not associated with germ cell neoplasia in situ (GCNIS) (10). Other reported pediatric tumor types include stromal tumors like Sertoli cell tumor, Leydig cell tumor, and juvenile granulosa cell tumors, which generally behave in a benign fashion in pre-pubertal patients. Pure yolk sac tumor is the most commonlyencountered malignant tumor among pre-pubertal patients $(3,7)$. Given the higher likelihood of benign lesions in this population, a clear shift towards a testis-sparing approach has been observed for pre-pubertal patients. For benign testis tumors, partial orchiectomy offers a durable cure with and may allow preservation of long-term hormonal 
function, fertility and quality of life (11-14).

For pre-pubertal patients diagnosed with a malignant testis tumor or post-pubertal males, who are more likely to have malignant tumors, radical inguinal orchiectomy remains the gold standard for initial treatment. More recently however, there have been increasing reports of testis-sparing approaches for adult patients with incidentally-detected small testicular masses, based upon studies suggesting smaller tumor size may correlate with a higher likelihood of benign pathology. Partial orchiectomy with adjuvant radiation therapy has also been advocated in carefully-selected adult patients with bilateral malignant testis tumors or tumors in a solitary testicle (15-18). It remains unclear if these practices can be safely extrapolated to post-pubertal pediatric patients, and radical inguinal orchiectomy is generally undertaken unless there is a very high suspicion for a benign lesion.

\section{Patient evaluation and selection}

The age of the patient, presentation and specific findings on evaluation aid in the selection of patients for a testis-sparing approach. Physical exam may reveal a firm, painless intrascrotal mass, testicular enlargement, and/or an associated hydrocele. Signs of virilization in a pre-pubertal patient or gynecomastia may support the presence of a Leydig cell tumor, Sertoli cell tumor or testicular adrenal rests associated with congenital adrenal hyperplasia $(19,20)$. While pre-pubertal patients are more likely to have a benign tumor, a testis mass in a post-pubertal patient has a much higher potential of being malignant.

Scrotal ultrasound (US) with Doppler is useful in characterizing the size and appearance of the mass and confirming it is a testis tumor $v s$. an extra-testicular process. US is unable to reliably distinguish between benign and malignant tumors, however certain features may be predictive of histology $(6,21)$. Most cystic lesions in children are benign (22). Well-circumscribed lesions containing hypoechoic or anechoic cystic areas with adjacent hyperechogenic and solid areas surrounded by normal testicular tissue are characteristic of teratoma $(10,23)$. Calcifications may also be present within the tumor, which allow differentiation from granulosa cell tumors (24). Epidermoid cysts may demonstrate an "onion-skin" or targetoid appearance, owing to deposition of layers of keratin debris within the cyst $(25,26)$ and are always benign. Juvenile granulosa cell tumors may appear as discrete multi-septated hypoechoic cystic lesions reminiscent of
"Swiss-cheese", while yolk sac tumors and other malignant lesions tend to demonstrate hypervascularity and a more solid appearance $(27,28)$. While multiple adult series have suggested a higher likelihood of benign histology for small testicular masses, a recent report on 24 pediatric and adolescent patients did not find that a tumor size of $<2 \mathrm{~cm}$ accurately predicted final pathology in this population $(15,16,18,29)$. It should also be noted that the amount of normal residual parenchyma on preoperative US should not be used as a factor in determining the appropriateness of partial orchiectomy, as the true volume of normal testicular parenchyma is often underestimated (30).

As with adult patients, measurement of tumor markers is paramount in the evaluation of a pediatric testis mass. Serum alpha-fetoprotein (AFP) is secreted by yolk sac tumors, which account for virtually all malignant testis tumors in pre-pubertal patients. Serum AFP is elevated in $90 \%$ of children with yolk sac tumor, making it a sensitive and useful marker for diagnosis and surveillance (28). It should be noted that serum AFP levels are typically elevated to the tens of thousands $(\mathrm{ng} / \mathrm{mL})$ at birth, decreasing to normal levels during the first year of life, and may therefore be a confounding factor in a young infant with a testis tumor (31). A review of the Pre-pubertal Testis Tumor Registry found considerable overlap in AFP levels among infants $<6$ months old with teratoma versus a yolk sac tumor; however after age 6 months, all patients with AFP levels less than $100 \mathrm{ng} / \mathrm{mL}$ harbored a teratoma (3). This finding may provide guidance towards consideration of a testis-sparing approach. In general however, an elevated AFP level in a child older than 1 year almost always indicates the presence of a yolk sac tumor, and radical orchiectomy should be performed. Although not typically helpful in the evaluation of pre-pubertal patients, human chorionic gonadotropin (HCG) is an important marker in adolescent and young adult patients and is elaborated by several malignant germ cell tumors including seminoma, choriocarcinoma and embryonal carcinoma (32).

\section{Specific indications for partial orchiectomy and consideration of a testis-sparing approach}

\section{Pre-pubertal testis tumors}

Several reviews have since documented a predominance of benign testicular lesions (48-74\%) in pre-pubertal patients, with teratoma comprising the most common histology (6-9). In general, given the increased likelihood for benign 
pathology, a testis-sparing approach should be considered in a pre-pubertal patient with a normal age-adjusted AFP level. Partial orchiectomy is performed if benign histology is encountered on intra-operative frozen section, while a radical orchiectomy is performed if malignancy is detected. Partial orchiectomy has since been described in numerous reports as a safe and effective modality for the management of a various benign testicular neoplasms including teratoma, epidermoid cyst, Sertoli cell tumor, Leydig cell tumor, Juvenile granulosa cell tumor, simple intra-testicular cyst, tubular ectasia of the rete testes, and testicular adrenal rest tumors $(6,8,9,12,14)$.

\section{Post-pubertal patients}

Testicular tumors occur more frequently in post-pubertal males and are also much more likely to be malignant. Mixed germ cell tumor is the most common histology in adolescent and young adult patients, as opposed to pure yolk sac tumor, which accounts for $98 \%$ of malignant pre-pubertal testis tumors (7). Radical orchiectomy is therefore the initial treatment of choice for a testicular tumor occurring a post-pubertal patient, and a testissparing approach is not routinely unless there is a high degree of certainty of encountering a benign lesion. In an effort to decrease the potential significant morbidity of testicular loss, experience with testis-sparing surgery is being described with greater frequency in the adult population. Partial orchiectomy has been successfully utilized for the management of adult benign testis masses including stromal tumors, epidermoid cysts, and fibrous pseudotumors (33-36). Recently, there have been increasing reports of partial orchiectomy in adult patients with small and/or incidentally-detected testicular masses, which have a higher likelihood of benign pathology (15,16,37-39). Various definitions of small testicular mass have been used, and in general, smaller tumors correlate with a higher likelihood of benign histology. Amongst these studies, masses $<2 \mathrm{~cm}$ had a $50-80 \%$ chance of being benign. Data in the adolescent population remain scarce, however and to date, only one study has attempted to correlate tumor size with histology in this cohort of patients. Using a $2 \mathrm{~cm}$ threshold, the authors did not find this size cut-off provided an accurate prediction of pathology that could guide the appropriateness of partial orchiectomy in either pre- or post-pubertal patients (18). Their group presently only considers a testis-sparing approach in carefully-selected post-pubertal patients with masses $<2 \mathrm{~cm}$ and normal tumor markers. Partial orchiectomy is performed if frozen section reveals benign histology, and radical orchiectomy is completed if malignancy is detected $(40,41)$.

The use of partial orchiectomy in the setting of malignant germ cell tumor remains controversial but has been advocated in carefully-selected adult patients with either bilateral testis tumors or tumor in a solitary testis (42-45). The high incidence of associated GCNIS in the remaining testicular parenchyma (80-98\%) must be emphasized, and adjuvant radiation is recommended for all patients undergoing partial orchiectomy for malignancy $(46,47)$. Close surveillance is mandatory, and the risk of infertility and need for androgen replacement may be unavoidable, particularly after radiotherapy. Patients must be adequately counseled on these risks. Partial orchiectomy has also been described for malignant germ cell tumor in the presence of a normal contralateral testis in a single series of 9 patients. The mean follow-up time was $41 \pm 20$ months. No patients developed distant metastasis, and survival was $100 \%$, however 1 patient had local recurrence at 39 months and underwent radical orchiectomy. Patients did not receive adjuvant radiation in this study, and authors attributed their low recurrence rate to a decreased incidence of GCNIS when tumors are $<2 \mathrm{~cm}$ (48). To date, there are no other published trials examining the overall safety of this practice, which deviates from clearly defined treatment standards. The importance of intraoperative US and the requirement of frozen section examination are emphasized in all reports and are discussed further in the section on operative technique.

While much of the management of post-pubertal testicular tumors has been extrapolated from adult data, the general applicability of these newer operative practices to post-pubertal pediatric patients remains unclear. Oncologic control should not be compromised, but the adoption of these practices in the adolescent population, in whom preservation of future hormonal and reproductive function are high priorities, must be considered. Prospective studies examining long term outcomes related to safety, fertility and adequacy of androgen production, after partial orchiectomy for small testicular masses in adult patients, are needed to guide practice changes in the pediatric population.

\section{Operative technique}

The technique for partial orchiectomy has been welldescribed for both the pediatric and adult patients. After proper patient selection and once the decision has been 


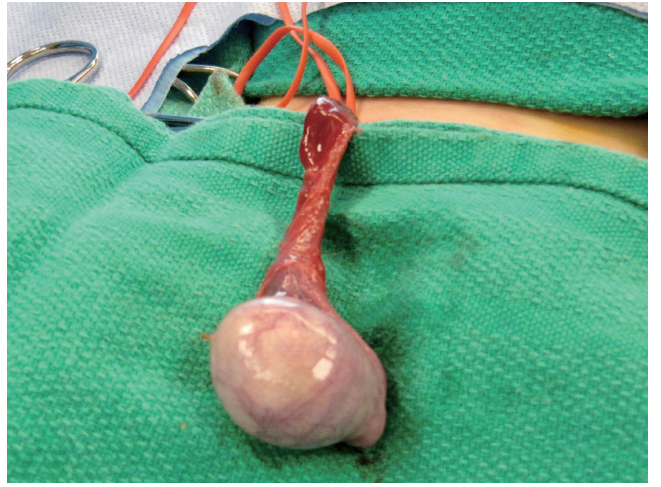

Figure 1 The testis is delivered through an inguinal incision.

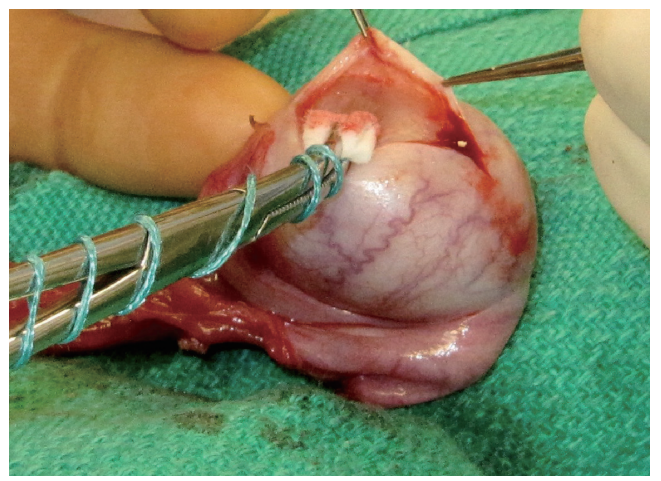

Figure 2 The tunica vaginalis is opened, and the tumor is enucleated or sharply excised.

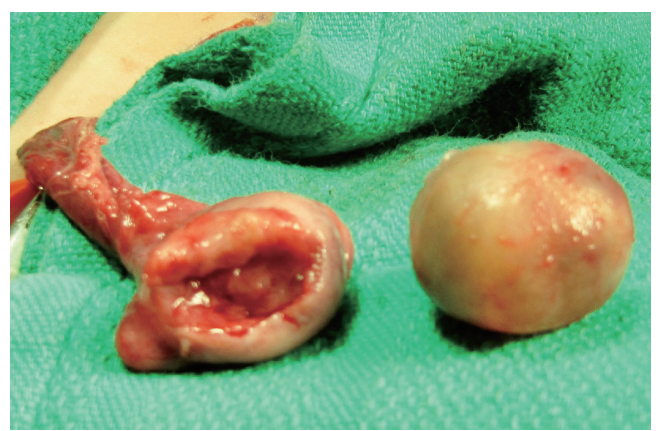

Figure 3 Partial orchiectomy specimen and testis showing the resection defect.

made for a testis-sparing approach, adequate counseling regarding the possibility of radical orchiectomy is important. It must be emphasized that consideration for testis-sparing does not obviate the possibility of orchiectomy, however the steps of the approach allow for possible testicular-sparing in the event of benign histology, and avoids compromising oncologic principles should malignancy be encountered. The need for expeditious frozen section should be communicated to pathology, and if necessary, intraoperative US should be readily available for tumor localization (14).

The initial steps for partial orchiectomy are the same as for radical orchiectomy, beginning with an inguinal incision, incision of the external oblique fascia and mobilization/ delivery of the testis into incision. Atraumatic occlusion of the cord with a soft tourniquet has been historically described. Recent data have suggested that clamping of the spermatic cord may not be necessary, and that the risk of tumor spread is less related to physical manipulation of the testis than to inherent tumor characteristics $(33,42,49)$. The practice of immersing the testis in crushed ice after cord occlusion, to achieve cold ischemia, has been advocated by some but remains controversial $(42,45,50)$. After delivery of the testis (Figure 1), the operative field is draped with towels in the event of tumor spillage, and the tunica vaginalis is opened. The mass is localized by palpation, however intraoperative US may facilitate the localization of deeper tumors. High resolution, high frequency US $(12 \mathrm{MHz})$ with capabilities of focusing, fine-tuning, and scale regulation is recommended (51). A needle can then be placed adjacent to the mass as a localizing marker (52). The tumor is enucleated or sharply excised (Figures 2 and 3) with a rim of normal parenchyma and sent for frozen section examination. If frozen section confirms benign histology, the tunica albuginea is repaired with fine, absorbable suture, and the testis is returned to the scrotum (Figure 4). If malignancy is detected, radical orchiectomy is completed by high ligation of the spermatic cord at the internal ring. If a radical orchiectomy is not performed despite malignancy on frozen section (e.g., in the setting of bilateral tumors or tumor in a solitary testis), biopsies of the surrounding tissue should be obtained to evaluate for other foci of malignancy and the presence of GCNIS on permanent histology.

Frozen section is a key component of partial orchiectomy, has both high specificity and sensitivity in differentiating between benign and malignant masses, and demonstrates excellent correlation with final histopathology (53-57). Though one study reported a $10 \%$ failure rate in accurately distinguishing between seminomatous and nonseminomatous tumors, this did not ultimately affect the choice of surgical management (56). A dedicated uropathologist, familiar with testicular histology likely increases the reliability of analysis, which is almost certainly greater 


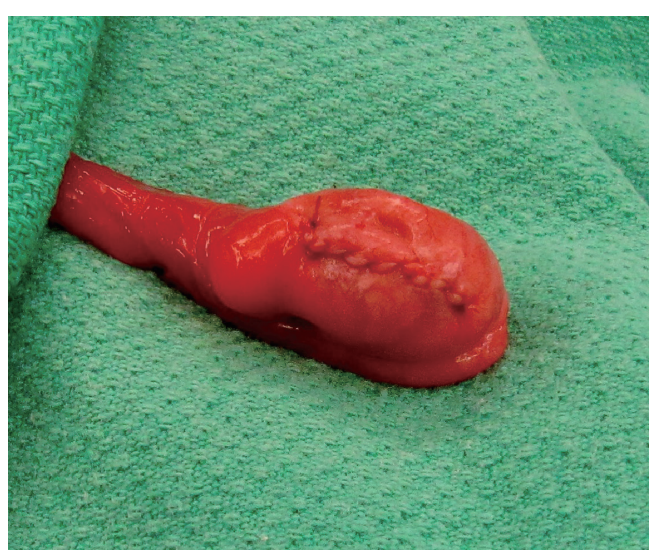

Figure 4 The testis is repaired with fine, absorbable suture.

at higher-volume referral centers (58).

\section{Functional outcomes}

Long-term functional outcomes in pediatric patients after radical or partial orchiectomy are lacking. For adults treated for malignant testicular neoplasms, the long term effects of chemotherapy, surgery, and radiation have an additional impact on gonadal function, fertility, and quality of life. Some data suggest that the loss of only one testicle may result in decreased spermatogenesis, insufficient androgen production, and a negative body image $(59,60)$. Furthermore, a significant proportion of patients with germ cell tumors may demonstrate underlying impaired fertility at baseline $(61,62)$. Preservation of as much testicular tissue as possible through testis-sparing surgery is therefore reasonable, if oncologic control is not compromise. For patients undergoing partial orchiectomy for benign lesions, multiple studies have documented successful preservation of testicular parenchyma, without evidence of atrophy or tumor recurrence after mean follow-up times of 5-10 years $(6,9,30,63)$. This may serve as a surrogate for preservation of ultimate function. Adult studies primarily in patients undergoing bilateral procedures or partial orchiectomy in a solitary testis have demonstrated adequate postoperative testosterone levels in the majority of patients $(45,52)$. In a large series of 101 patients, 85 patients had GCNIS, and 80 underwent radiotherapy. Ten patients required androgen supplementation for de novo hypogonadism, and 4 patients successfully achieved paternity with delayed adjuvant radiation (47). In the second largest series of 11 patients, 10 had GCNIS, with 8 undergoing radiotherapy. Only one patient, noted to have a $3 \mathrm{~cm}$ mixed germ cell tumor, who received adjuvant radiation, developed androgen insufficiency and testicular atrophy during the mean followup time of 60 months (45). Most reviews cite the need for future prospective multi-center studies to better determine overall long-term functional outcomes after partial orchiectomy.

\section{Conclusions}

The predominance of benign testis tumors in pre-pubertal patients, coupled with the high reliability of serum tumor markers, scrotal US and intraoperative frozen section, have resulted in a marked shift towards a testicularsparing approach with partial orchiectomy in this patient population. More recently, this approach has been reported in carefully-selected post-pubertal patients as well, in an effort to avoid overtreatment of potentially benign lesions. Radical orchiectomy remains the standard of care for malignant testicular tumors, and any deviation from established guidelines must be exercised with a high level of caution. Future studies must focus on functional outcomes after partial orchiectomy in this patient population, with the goal of maximizing fertility preservation and avoiding the morbidity of hypogonadism, without sacrificing oncologic control.

\section{Take-home points}

* Radical inguinal orchiectomy is the gold-standard for the management of malignant testis tumors.

- In pre-pubertal patients with a testis mass and normal AFP, a testis-sparing approach is appropriate.

- Caution should be exercised when considering a testissparing approach for a post-pubertal testicular mass.

* Frozen section exam with confirmation of benign histology is a key component of partial orchiectomy.

\section{Acknowledgments}

Funding: None.

\section{Footnote}

Provenance and Peer Review: This article was commissioned by the Guest Editors (John Wiener, Jonathan Routh and Nicholas Cost) for the series "Pediatric Urologic Malignancies" published in Translational Andrology and Urology. The article was sent for external peer review 
organized by the Guest Editors and the editorial office.

Conflicts of Interest: Both authors have completed the ICMJE uniform disclosure form (available at http://dx.doi. org/10.21037/tau-19-815). The series "Pediatric Urologic Malignancies" was commissioned by the editorial office without any funding or sponsorship. The authors have no conflicts of interest to declare.

Ethical Statement: The authors are accountable for all aspects of the work in ensuring that questions related to the accuracy or integrity of any part of the work are appropriately investigated and resolved.

Open Access Statement: This is an Open Access article distributed in accordance with the Creative Commons Attribution-NonCommercial-NoDerivs 4.0 International License (CC BY-NC-ND 4.0), which permits the noncommercial replication and distribution of the article with the strict proviso that no changes or edits are made and the original work is properly cited (including links to both the formal publication through the relevant DOI and the license). See: https://creativecommons.org/licenses/by-nc-nd/4.0/.

\section{References}

1. Kay R. Prepubertal Testicular Tumor Registry. J Urol 1993;150:671-4.

2. Schneider DT, Calaminus G, Koch S, et al. Epidemiologic analysis of 1,442 children and adolescents registered in the German germ cell tumor protocols. Pediatr Blood Cancer 2004;42:169-75.

3. Ross JH, Rybicki L, Kay R. Clinical behavior and a contemporary management algorithm for prepubertal testis tumors: a summary of the Prepubertal Testis Tumor Registry. J Urol 2002;168:1675-8; discussion 1678-9.

4. Alanee S, Shukla A. Paediatric testicular cancer: an updated review of incidence and conditional survival from the Surveillance, Epidemiology and End Results database. BJU Int 2009;104:1280-3.

5. Weissbach L, Altwein JE, Stiens R. Germinal testicular tumors in childhood. Report of observations and literature review. Eur Urol 1984;10:73-85.

6. J.S. Valla for the Group D'Etude en Urologie Pediatrique. Testis-sparing surgery for benign testicular tumors in children. J Urol 2001;165:2280-3.

7. Pohl HG, Shukla AR, Metcalf PD, et al. Prepubertal testis tumors: actual prevalence rate of histological types. J Urol
2004;172:2370-2.

8. Metcalfe PD, Farivar-Mohseni H, Farhat W, et al. Pediatric testicular tumors: contemporary incidence and efficacy of testicular preserving surgery. J Urol 2003;170:2412-5; discussion 2415-6.

9. Shukla AR, Woodard C, Carr MC, et al. Experience with testis sparing surgery for testicular teratoma. J Urol 2004;171:161-3.

10. Rushton HG, Belman AB, Sesterhenn I, et al. Testicular sparing surgery for prepubertal teratoma of the testis: a clinical and pathological study. J Urol 1990;144:726-30.

11. Ross JH, Kay R. Prepubertal testis tumors. Rev Urol 2004;6:11-8.

12. Bujons A, Sfulcini JC, Pascual M, et al. Prepubertal testicular tumours and efficacy of testicular preserving surgery. BJU Int 2011;107:1812-6.

13. Ciftci AO, Bingol-Kologlu M, Senocak ME, et al. Testicular tumors in children. J Pediatr Surg 2001;36:1796-801.

14. Makari JH, Ramachandra P, Ferrer FA Jr. Pediatric urologic oncology: organ-sparing surgery in kidney and testis. Urol Clin North Am 2010;37:287-98.

15. Borghesi M, Brunocilla E, Schiavina R, et al. Role of testis sparing surgery in the conservative management of small testicular masses: oncological and functional perspectives. Actas Urol Esp 2015;39:57-62.

16. Brunocilla E, Gentile G, Schiavina R, et al. Testis-sparing surgery for the conservative management of small testicular masses: an update. Anticancer Res 2013;33:5205-10.

17. Gentile G, Brunocilla E, Franceschelli A, et al. Can testis-sparing surgery for small testicular masses be considered a valid alternative to radical orchiectomy? A prospective single-center study. Clin Genitourin Cancer 2013;11:522-6.

18. Caldwell BT, Saltzman AF, Maccini MA, et al. Appropriateness for testis-sparing surgery based on the testicular tumor size in a pediatric and adolescent population. J Pediatr Urol 2019;15:70.e1-70.e6.

19. Walker BR, Skoog SJ, Winslow BH, et al. Testis sparing surgery for steroid unresponsive testicular tumors of the adrenogenital syndrome. J Urol 1997;157:1460-3.

20. Thomas JC, Ross JH, Kay R. Stromal testis tumors in children: a report from the prepubertal testis tumor registry. J Urol 2001;166:2338-40.

21. Tallen G, Hernaiz Driever P, Degenhardt P, et al. High reliability of scrotal ultrasonography in the management of childhood primary testicular neoplasms. Klin Padiatr 2011;223:131-7. 
22. Liniger B, Fleischmann A, Zachariou Z. Benign cystic lesions in the testis of children. J Pediatr Urol 2012;8:226-33.

23. Koski ME, Thomas JC. Successful bilateral testicular sparing surgery for benign teratoma. J Pediatr Urol 2009;5:72-4.

24. Carver BS, Al-Ahmadie H, Sheinfeld J. Adult and pediatric testicular teratoma. Urol Clin North Am 2007;34:245-51; abstract $\mathrm{x}$.

25. Ross JH, Kay R, Elder J. Testis sparing surgery for pediatric epidermoid cysts of the testis. J Urol 1993;149:353-6.

26. Lev R, Mor Y, Leibovitch I, et al. Epidermoid cyst of the testis in an adolescent: Case report and review of the evolution of the surgical management. J Pediatr Surg 2002;37:121-3.

27. Wei $\mathrm{Y}, \mathrm{Wu} \mathrm{S}$, Lin T, et al. Testicular yolk sac tumors in children: a review of 61 patients over 19 years. World J Surg Oncol 2014;12:400,7819-12-400.

28. Ross JH. Prepubertal testicular tumors. Urology 2009;74:94-9.

29. Heidenreich A, Bonfig R, Derschum W, et al. A conservative approach to bilateral testicular germ cell tumors. J Urol 1995;153:10-3.

30. Patel AS, Coley BD, Jayanthi VR. Ultrasonography underestimates the volume of normal parenchyma in benign testicular masses. J Urol 2007;178:1730-2.

31. Wu JT, Book L, Sudar K. Serum alpha fetoprotein (AFP) levels in normal infants. Pediatr Res 1981;15:50-2.

32. Smith ZL, Werntz RP, Eggener SE. Testicular Cancer: Epidemiology, Diagnosis, and Management. Med Clin North Am 2018;102:251-64.

33. Leonhartsberger N, Pichler R, Stoehr B, et al. Organ preservation technique without ischemia in patients with testicular tumor. Urology 2014;83:1107-11.

34. Heidenreich A, Engelmann UH, Vietsch HV, et al. Organ preserving surgery in testicular epidermoid cysts. J Urol 1995; 153:1147-50.

35. Giannarini G, Mogorovich A, Menchini Fabris F, et al. Long-term follow up after elective testis sparing surgery for Leydig cell tumors: a single center experience. J Urol 2007;178:872-6; quiz 1129.

36. Bozzini G, Picozzi S, Gadda F, et al. Long-term follow-up using testicle-sparing surgery for Leydig cell tumor. Clin Genitourin Cancer 2013;11:321-4.

37. Shilo Y, Zisman A, Raz O, et al. Testicular sparing surgery for small masses. Urol Oncol 2012;30:188-91.

38. Keske M, Canda AE, Yalcin S, et al. Is testis-sparing surgery safe in small testicular masses? Results of a multicentre study. Can Urol Assoc J 2017;11:E100-4.

39. Scandura G, Verrill C, Protheroe A, et al. Incidentally detected testicular lesions $<10 \mathrm{~mm}$ in diameter: can orchidectomy be avoided? BJU Int 2018;121:575-82.

40. Saltzman AF, Cost NG. Adolescent and Young Adult Testicular Germ Cell Tumors: Special Considerations. Adv Urol 2018;2018:2375176.

41. Caldwell BT, Wilcox DT, Cost NG. Current Management for Pediatric Urologic Oncology. Adv Pediatr 2017;64:191-223.

42. Heidenreich A, Weissbach L, Holtl W, et al. Organ sparing surgery for malignant germ cell tumor of the testis. J Urol 2001;166:2161-5.

43. Weissbach L. Organ preserving surgery of malignant germ cell tumors. J Urol 1995;153:90-3.

44. Lawrentschuk N, Zuniga A, Grabowksi AC, et al. Partial orchiectomy for presumed malignancy in patients with a solitary testis due to a prior germ cell tumor: a large North American experience. J Urol 2011;185:508-13.

45. Steiner H, Holtl L, Maneschg C, et al. Frozen section analysis-guided organ-sparing approach in testicular tumors: technique, feasibility, and long-term results. Urology 2003;62(3:508-13.

46. Albers $\mathrm{P}$, Albrecht $\mathrm{W}$, Algaba F, et al. EAU guidelines on testicular cancer: 2011 update. Eur Urol 2011;60:304-19.

47. Heidenreich A, Albers P, Krege S. Management of bilateral testicular germ cell tumors - experience of the German testicular cancer study group (GTCSG) [abstract 299]. Eur Urol Suppl 2006;5:97.

48. Bojanic N, Bumbasirevic U, Bojanic G, et al. Testis sparing surgery for treatment of small testicular lesions: Is it feasible even in germ cell tumors? J Surg Oncol 2017;115:287-90.

49. Albers P. Organ-sparing surgery for testicular lesions. Eur Urol Suppl 2006;5:522-4.

50. Hallak J, Cocuzza M, Sarkis AS, et al. Organ-sparing microsurgical resection of incidental testicular tumors plus microdissection for sperm extraction and cryopreservation in azoospermic patients: surgical aspects and technical refinements. Urology 2009;73:887-91; discussion 891-2.

51. Galosi AB, Fulvi P, Fabiani A, et al. Testicular sparing surgery in small testis masses: A multinstitutional experience. Arch Ital Urol Androl 2016;88:320-4.

52. Leonhartsberger N, Pichler R, Stoehr B, et al. Organsparing surgery is the treatment of choice in benign testicular tumors. World J Urol 2014;32:1087-91.

53. Leroy X, Rigot JM, Aubert S, et al. Value of frozen section 
examination for the management of nonpalpable incidental testicular tumors. Eur Urol 2003;44:458-60.

54. Subik MK, Gordetsky J, Yao JL, et al. Frozen section assessment in testicular and paratesticular lesions suspicious for malignancy: its role in preventing unnecessary orchiectomy. Hum Pathol 2012;43:1514-9.

55. Connolly SS, D'Arcy FT, Bredin HC, et al. Value of frozen section analysis with suspected testicular malignancy. Urology 2006;67:162-5.

56. Elert A, Olbert P, Hegele A, et al. Accuracy of frozen section examination of testicular tumors of uncertain origin. Eur Urol 2002;41:290-3.

57. Matei DV, Vartolomei MD, Renne G, et al. Reliability of Frozen Section Examination in a Large Cohort of Testicular Masses: What Did We Learn? Clin Genitourin Cancer 2017;15:e689-96.

58. Giannarini G, Dieckmann KP, Albers P, et al. Organsparing surgery for adult testicular tumours: a systematic

Cite this article as: Woo LL, Ross JH. Partial orchiectomy vs. radical orchiectomy for pediatric testis tumors. Transl Androl Urol 2020;9(5):2400-2407. doi:10.21037/tau-19-815 review of the literature. Eur Urol 2010;57:780-90.

59. Ferreira U, Netto Junior NR, et al. Comparative study of the fertility potential of men with only one testis. Scand J Urol Nephrol 1991;25:255-9.

60. Huddart RA, Norman A, Moynihan C, et al. Fertility, gonadal and sexual function in survivors of testicular cancer. Br J Cancer 2005;93:200-7.

61. Dieckmann KP, Linke J, Pichlmeier U, et al. Spermatogenesis in the contralateral testis of patients with testicular germ cell cancer: histological evaluation of testicular biopsies and a comparison with healthy males. BJU Int 2007;99:1079-85.

62. Yossepowitch O, Baniel J. Role of organ-sparing surgery in germ cell tumors of the testis. Urology 2004;63:421-7.

63. Sugita Y, Clarnette TD, Cooke-Yarborough C, et al. Testicular and paratesticular tumours in children: 30 years' experience. Aust N Z J Surg 1999;69:505-8. 